2015

\title{
Marine extinction risk shaped by trait-environment interactions over 500 million years
}

\author{
Emily A. Orzechowski \\ Seth Finnegan \\ David R. Lindberg \\ Rowan Lockwood \\ College of William and Mary
}

Follow this and additional works at: https://scholarworks.wm.edu/aspubs

\section{Recommended Citation}

Orzechowski, E. A., Lockwood, R., Byrnes, J. E., Anderson, S. C., Finnegan, S., Finkel, Z. V., ... \& McClain, C. R. (2015). Marine extinction risk shaped by trait-environment interactions over 500 million years. Global change biology, 21(10), 3595-3607.

This Article is brought to you for free and open access by the Arts and Sciences at W\&M ScholarWorks. It has been accepted for inclusion in Arts \& Sciences Articles by an authorized administrator of W\&M ScholarWorks. For more information, please contact scholarworks@wm.edu. 


\title{
Marine extinction risk shaped by trait-environment interactions over 500 million years
}

\author{
EMILY A. ORZECHOWSKI ${ }^{1}$, ROWAN LOCKWOOD ${ }^{2}$, JARRETT E. K. BYRNES ${ }^{3}$, \\ SEAN C. ANDERSON ${ }^{4}$, SETH FINNEGAN ${ }^{1}$, ZOEV.FINKEL ${ }^{5}$, PAULG. HARNIK ${ }^{6}$, \\ DAVID R. LINDBERG ${ }^{1}$, LEE HSIANG LIOW ${ }^{7}$, HEIKEK. LOTZE ${ }^{8}$, CRAIG R. MCCLAIN $^{9}$, \\ JENNYL. MCGUIRE ${ }^{10}$, AARON O'DEA ${ }^{11}$, JOHN M. PANDOLFI ${ }^{12}$, CARL SIMPSON $^{13}$ and \\ DEREK P. TITTENSOR ${ }^{14,15}$ \\ ${ }^{1}$ Department of Integrative Biology and Museum of Paleontology, University of California, Berkeley, CA 94720, USA, \\ ${ }^{2}$ Department of Geology, College of William and Mary, Williamsburg, VA 23187, USA, ${ }^{3}$ Biology Department, University of \\ Massachusetts Boston, 100 Morrissey Blvd, Boston, MA 02125, USA, ${ }^{4}$ Department of Biological Sciences, Simon Fraser \\ University, Burnaby, BC V5A 1S6, Canada, ${ }^{5}$ Environmental Science Program, Mount Allison University, Sackville, NB E4L 1A5, \\ Canada, ${ }^{6}$ Department of Earth and Environment, Franklin and Marshall College, Lancaster, PA 17604, USA, ${ }^{7}$ Center for \\ Ecological and Evolutionary Synthesis, Department of Biosciences, University of Oslo, Blindern, N-0316 Oslo, Norway, \\ ${ }^{8}$ Department of Biology, Dalhousie University, 1355 Oxford Street, P.O. Box 15000, Halifax, NS B3H 4R2, Canada, ${ }^{9}$ National \\ Evolutionary Synthesis Center, Durham, NC 27705, USA, ${ }^{10}$ School of Biology, Georgia Institute of Technology, Atlanta, GA \\ 30332, USA, ${ }^{11}$ Smithsonian Tropical Research Institute, 0843-03092, Balboa, Republic of Panamá, ${ }^{12}$ Australian Research Council \\ Centre of Excellence for Coral Reef Studies, School of Biological Sciences, The University of Queensland, Brisbane, Qld 4072, \\ Australia, ${ }^{13}$ Department of Paleobiology, Smithsonian Institution, P.O. Box 37012 MRC-121, Washington, DC 20013-7012, USA, \\ ${ }^{14}$ Department of Biology, Dalhousie University, 1355 Oxford Street, P.O. Box 15000, Halifax, NS B3H 4R2, Canada, ${ }^{15}$ United \\ Nations Environment Programme World Conservation Monitoring Centre, 219 Huntingdon Road, Cambridge CB3 0DL, \\ UK
}

\begin{abstract}
Perhaps the most pressing issue in predicting biotic responses to present and future global change is understanding how environmental factors shape the relationship between ecological traits and extinction risk. The fossil record provides millions of years of insight into how extinction selectivity (i.e., differential extinction risk) is shaped by interactions between ecological traits and environmental conditions. Numerous paleontological studies have examined trait-based extinction selectivity; however, the extent to which these patterns are shaped by environmental conditions is poorly understood due to a lack of quantitative synthesis across studies. We conducted a meta-analysis of published studies on fossil marine bivalves and gastropods that span 458 million years to uncover how global environmental and geochemical changes covary with trait-based extinction selectivity. We focused on geographic range size and life habit (i.e., infaunal vs. epifaunal), two of the most important and commonly examined predictors of extinction selectivity. We used geochemical proxies related to global climate, as well as indicators of ocean acidification, to infer average global environmental conditions. Life-habit selectivity is weakly dependent on environmental conditions, with infaunal species relatively buffered from extinction during warmer climate states. In contrast, the odds of taxa with broad geographic ranges surviving an extinction ( $>2500 \mathrm{~km}$ for genera, $>500 \mathrm{~km}$ for species) are on average three times greater than narrow-ranging taxa (estimate of odds ratio: $2.8,95 \%$ confidence interval $=2.3-3.5$ ), regardless of the prevailing global environmental conditions. The environmental independence of geographic range size extinction selectivity emphasizes the critical role of geographic range size in setting conservation priorities.
\end{abstract}

Keywords: differential extinction risk, extinction selectivity, geographic range, life habit, mass extinction, mollusk, survivorship Received 16 January 2015; revised version received 8 April 2015 and accepted 10 April 2015

\section{Introduction}

Anthropogenic climate change is rapidly altering oceanic temperature, $\mathrm{pH}$, carbonate saturation state (Caldeira \& Wickett, 2003; Orr et al., 2005; Hoegh-

Correspondence: Rowan Lockwood, tel. +1 757272 2125, fax

+1 757221 2093, e-mail: rxlock@wm.edu
Guldberg et al., 2007), circulation (Broecker, 1997), and oxidation state (Shaffer et al., 2009). Predicting which marine taxa will persist in the face of these changes requires an understanding of the differential extinction risk among extant marine organisms, especially the wide swathe of groups that are not commercially exploited (Harnik et al., 2012a; McClenachan et al., 2012; Finnegan et al., 2015). Differential extinction risk, 
referred to here as 'extinction selectivity', is defined as the identification of traits that distinguish taxa that go extinct from taxa that survive across a particular extinction event or time interval (Lockwood, 2008).

Much of what we know about extinction selectivity in the marine realm is derived from the rich fossil record of benthic marine invertebrates. Paleontological studies provide empirical support for the influence of a number of biological factors on extinction selectivity over the $>500$-million-year history of skeletonized marine animals (e.g., Jablonski, 2005; Kiessling \& Aberhan, 2007; Knoll et al., 2007; Liow, 2007; Payne \& Finnegan, 2007; O'Dea \& Jackson, 2009; Simpson \& Harnik, 2009; Crampton et al., 2010; Finnegan et al., 2012; Harnik et al., 2012b). The extent to which biological characteristics have influenced extinction selectivity, and changes in environmental state have amplified or weakened these effects, is valuable information for predicting extinction selectivity given future environmental conditions (Harnik et al., 2012a; Blois et al., 2013). Quantitative synthesis of the sizeable literature on extinction selectivity in the fossil record has never been attempted and is an important step toward leveraging the fossil record to understand drivers of extinction selectivity among marine taxa today.

Despite the extensive literature on extinction selectivity in the fossil record, few studies have incorporated environmental proxy data into the analyses, leaving the question of whether environmental conditions affect selectivity in a consistent manner unanswered. This likely stems from the fact that most studies assess extinction selectivity over a relatively narrow interval of time. Given that environmental conditions have varied dramatically through the Phanerozoic, studies of limited temporal scope cannot adequately address how selectivity is mediated by environmental conditions. In this study, we explicitly incorporate environmental proxy data and observed extinction rates into our model, allowing us to identify a possible link between extinction selectivity and global climate state.

We conducted a meta-analysis of the published literature on extinction selectivity and environmental conditions to determine whether clear and repeated patterns in selectivity emerge. Meta-analysis combines the results from many published sources into a synthetic effect size to test a given hypothesis (Cooper et al., 2009). Using this approach allowed us to capitalize on the expertise of many individual specialists whose combined work spans across the Phanerozoic (540 million years ago until the present) and assess how global-scale changes in environmental conditions influence trait-based extinction selectivity.

Here, we focus on benthic marine gastropods and bivalves. Numerous studies have examined selective extinction patterns in these taxa; the effects of preservational, sampling, and taxonomic biases are well understood (Valentine, 1989; Foote \& Raup, 1996; Harper, 1998; Foote \& Sepkoski, 1999; Kidwell, 2001, 2002, 2005; Cooper et al., 2006; Valentine et al., 2006; Wagner et al., 2007); and comparisons between molecular phylogenies and morphology-based taxonomy are generally congruent (e.g., Jablonski \& Finarelli, 2009). Many ecological traits have been examined in the context of extinction selectivity in fossil mollusks, including geographic range size, life habit, feeding mode, abundance, larval mode, and body size (for reviews see McKinney, 1997, 2001; Jablonski, 2005; Lockwood, 2008; Harnik \& Lockwood, 2011). However, the effects of geographic range and life habit (i.e., whether organisms live on the seafloor or burrow beneath it) on survivorship have received the most consistent attention.

Geographic range size is the most consistent predictor of extinction selectivity in modern taxa (Rosenzweig, 1995; Purvis et al., 2000; Jones et al., 2003; Brook et al., 2008), but previous studies have shown that the strength of the relationship between geographic range and extinction risk varies through time, a pattern which may reflect variations in environmental conditions or in overall extinction rate (Jablonski, 1986a; Payne \& Finnegan, 2007). The association between extinction risk and geographic range is generally expected to be negative (i.e., as the geographic range of a species increases, its extinction risk should decrease). For example, during the late Neogene, narrowly distributed species were more likely to become extinct in western South America (Rivadeneira \& Marquet, 2007) and tropical America (Roopnarine, 1997). However, in western North America, there is no evidence that extinction is selective with respect to geographic range at this time (Stanley, 1986a). Studies of extinction selectivity according to life-habit yield similarly variable results. Some extinction events appear to selectively eliminate infaunal taxa (i.e., organisms that burrow) (Gallagher, 1991; McRoberts \& Newton, 1995; Aberhan \& Baumiller, 2003), others eliminate epifaunal taxa (i.e., organisms living on the seafloor) (Crame, 2002; Knoll et al., 2007; Rivadeneira \& Marquet, 2007), while others display no apparent extinction selectivity according to life habit (Stanley, 1986a; Jablonski \& Raup, 1995; Crampton et al., 2010).

Global shifts in the temperature, productivity, $\mathrm{pH}$, or oxygenation of the oceans might be expected to exert an influence on the direction and/or magnitude of extinction selectivity. For example, an epifaunal life habit may be advantageous in coping with sudden changes in bottom-water food availability or oxygenation, the effects of which can be particularly severe below the sediment-water interface (Bacon et al., 1998; Velasco \& Navarro, 2003; Montagna \& Ritter, 2006). An 
infaunal life habit may be advantageous under normal geochemical conditions, when predation pressure on epifaunal organisms can be intense (Stanley, 1977, 1982, 1986a; Vermeij, 1987; see papers in Kowalewski, 2002; Kelley \& Hansen, 2003).

Changes in the pattern of extinction selectivity may also be affected by the sheer magnitude of the extinction event. Some studies suggest that traits that promote survivorship during intervals characterized by low extinction rates (i.e., background intervals) cease to be important during times of mass extinction (Jablonski, 1986a; Kitchell et al., 1986; Jablonski, 1989; Jablonski \& Raup, 1995; Lockwood, 2003; Payne \& Finnegan, 2007). Mass extinctions may impose very different selective regimes than background extinctions, in part because they represent extreme environmental conditions. This suggests that the choice of paleontological patterns to inform models of current and future selectivity will depend on the rate of current extinctions and how similar past environmental drivers of extinction are to those operating today and in the future.

In this study, we conducted a meta-analysis to test whether extinction in the Phanerozoic fossil record of marine bivalves and gastropods was selective according to geographic range size and/or life habit. We assessed whether extinction selectivity patterns exhibited a significant dependence on taxonomic level (species vs. genus), molluscan class (Bivalvia vs. Gastropoda), geographic scope (global vs. regional), and temporal resolution (single geological stage vs. multiple stages). We then assessed whether extinction selectivity varied according to the observed rate of the extinction and a range of proxies for environmental conditions, including conditions that are predicted to change over the next few decades (Rockström et al., 2009). These include proxies that are influenced by average climate state, carbon cycling, oxygenation, and $\mathrm{pH}$ of the global oceans.

\section{Materials and methods}

We conducted a series of meta-analyses to quantify patterns of extinction selectivity in the fossil record and to assess whether selectivity patterns exhibit a significant dependence on the values of environmental proxies. The meta-analyses incorporated data from previously published studies of species- and genus-level extinction selectivity for fossil bivalves and gastropods throughout the Phanerozoic (Table S1). We employed two approaches to surveying the literature: (i) searches targeting large and multi-disciplinary databases (Geoscience World, Google Scholar, and SpringerLink databases) using the following terms and combinations of terms ('extinction', 'selectivity', and 'bivalve/gastropod/mollusk') and (ii) a database of extinction selectivity studies compiled by Harnik \& Lockwood (2011). All studies are published in peer-reviewed sources. When authors published multiple studies, expanding on their dataset and duplicating tests, we included only the most recently published results. When the published data lacked the resolution or format required for our analysis, we emailed the authors and requested their raw data. Several authors generously provided data to make the meta-analysis possible (see Acknowledgements, Table S1).

Effect sizes in our meta-analysis were measured using the log-odds ratio (Mantel \& Haenszel, 1959; Cooper et al., 2009), which compares the ratio of victims (i.e., taxa that go extinct across an event) to survivors (i.e., taxa that survive an event) for species or genera falling into one geographic range size or life-habit category vs. the ratio of victims to survivors in the other category by the end of a particular time interval. In some cases, a single publication (e.g., McRoberts \& Newton, 1995; Aberhan \& Baumiller, 2003) yielded multiple effect sizes corresponding to different geological stages (i.e., time intervals), locations, and/or study organisms. The meta-analysis dataset contains 128 effect sizes total, spanning the Ordovician (485 Ma) to Pleistocene (Gelasian, 1.8 Ma). One hundred of these effect sizes are derived from data drawn from a single geological stage and 28 are derived from data spanning multiple geological stages. The dataset includes several regional events, as well as background and mass extinctions globally, compiled from 22 studies total (see Table S1). Temporal coverage includes 27 effect sizes from the Paleozoic (485 to $251 \mathrm{Ma}$ for this study), 44 from the Mesozoic (251 to $65.5 \mathrm{Ma}$ ), and 57 from the Cenozoic (65.5 to $0 \mathrm{Ma}$ ). The majority of the effect sizes (87) are regional in geographic scope and 41 are global.

We assigned taxa to geographic range size and life-habit categories based on the categories most commonly applied across published studies. We categorized geographic range of a taxon in the geological stage before an extinction event as either broad-ranging (maximum geographic extent of $>2500$ $\mathrm{km}$ for fossil occurrences of genera and $>500 \mathrm{~km}$ for fossil occurrences of species) or narrow-ranging (maximum geographic extent of $\leq 2500 \mathrm{~km}$ for fossil occurrences of genera and $\leq 500 \mathrm{~km}$ for fossil occurrences of species; Jablonski, 1986a, 2005). These cutoffs are commonly used in the paleontological literature (Jablonski, 1986a, 2005) and have been shown to represent the median geographic distribution of fossil bivalves and gastropods (Jablonski \& Lutz, 1983). However, when authors assessed geographic range using other categories, we used the raw data or measured the study area's maximal great circle distance extent to recategorize geographic range size. Great circle distances were calculated using paleocoordinates when necessary. Estimates of geographic range were taken from the studies themselves. We categorized life habit as either epifaunal or infaunal, based on the designations of the original authors (which in turn are based on the life habits of modern taxonomic representatives or preservation in life position of fossils). Our approach ensured that we applied the same definition of narrow vs. broad geographic range, and epifaunal vs. infaunal life habit, to all studies. 


\section{Calculating extinction selectivity}

To calculate the log-odds ratio (Mantel \& Haenszel, 1959; Cooper et al., 2009), we began with a $2 \times 2$ matrix describing the number of preserved and sampled species going extinct or surviving in either trait category. For example, a taxon is either epifaunal or infaunal and can either go extinct or survive. The odds ratio of extinction selectivity is the ratio of the probability of survival $\left(p_{1}\right)$ and extinction $\left(1-p_{1}\right)$ in one trait category divided by the ratio of survival $\left(p_{2}\right)$ and extinction $\left(1-p_{2}\right)$ in the other trait category. The extinction log-odds ratio (OR) is defined as:

$$
\ln (\mathrm{OR})=\ln \frac{p_{1} /\left(1-p_{1}\right)}{p_{2} /\left(1-p_{2}\right)} .
$$

If extinction is not selective for a trait category, the log-odds ratio is 0 . A positive log-odds ratio indicates greater odds of survival for group 1; a negative log-odds ratio indicates greater odds of survival for group 2. For the geographicrange-size comparison, we defined group 1 as broad-ranging taxa and group 2 as narrow-ranging taxa. For life habit, we defined group 1 as epifaunal taxa and group 2 as infaunal taxa. The standard error (SE) of the log-odds ratio from a single study is defined as:

$$
\mathrm{SE}=\sqrt{\frac{1}{s_{1}}+\frac{1}{e_{1}}+\frac{1}{s_{2}}+\frac{1}{e_{2}}}
$$

where $s_{1}$ and $s_{2}$ are the number of surviving taxa in groups 1 and 2 and $e_{1}$ and $e_{2}$ are the number of extinct taxa in groups 1 and 2 . The $95 \%$ confidence interval is then $\ln (\mathrm{OR}) \pm 1.96 \mathrm{SE}$.

\section{Proxies for environmental conditions and observed extinction rate}

To model the impact of environmental conditions on extinction selectivity, we matched a set of proxies and observed extinction rate with each effect size. We assessed the importance of three stable isotope proxies influenced by climate and ocean state, which may affect the associations between biological traits such as range size and life-habit and extinction selectivity: $\delta^{18} \mathrm{O}, \delta^{13} \mathrm{C}$, and $\delta^{34} \mathrm{~S}$ (Table S2). We obtained these data from Hannisdal \& Peters' (2011) treatment of the Phanerozoic biogenic carbonate data compiled by Prokoph et al. (2008). Following Prokoph et al. (2008) and Hannisdal \& Peters (2011), we divided the isotope data into high vs. low paleolatitudinal subsets for systems that are particularly sensitive to environmental heterogeneity $\left(\delta^{18} \mathrm{O}\right)$ and then focused on the low latitudinal subset, because it provided the most complete data coverage.

Climate change and corresponding sea-level fluctuations have been implicated as important drivers of biotic change in the marine fossil record and are associated with multiple severe extinction events (Newell, 1967; Hallam \& Wignall, 1999; Hannisdal \& Peters, 2011; Finnegan et al., 2012). The ratio of ${ }^{18} \mathrm{O}$ to ${ }^{16} \mathrm{O}\left(\delta^{18} \mathrm{O}\right)$ in marine carbonates is a function of both the temperature at which the mineral precipitated $\left({ }^{18} \mathrm{O}\right.$ is preferentially incorporated into the carbonate lattice at lower temperatures) and the isotopic composition of the water from which it precipitated. Therefore, we cannot interpret $\delta^{18} \mathrm{O}$ as a simple proxy for temperature without knowledge of the isotopic composition of seawater through time (Jaffrés et al., 2007). However, the major process responsible for altering the isotopic composition of seawater on geologically short $\left(<10^{7}\right.$ years $)$ timescales is the growth and decay of glaciers, which preferentially incorporate isotopically light water. Because global mean temperature and glacial ice volume are expected to be negatively correlated (Veizer et al., 1997), high (or heavy) $\delta^{18} \mathrm{O}$ values indicate relatively cool climate states and low (or light) $\delta^{18} \mathrm{O}$ values relatively warm climate states.

Major shifts in carbon cycling as recorded by $\delta^{13} \mathrm{C}$ frequently coincide with severe extinction events (Kump, 1991; Wignall et al., 2009; Stanley, 2010; Ruhl et al., 2011), and these shifts may impact the survivorship of different molluscan groups via geologically abrupt changes in primary productivity and nutrient cycling (Hollander et al., 1993). The ratio of ${ }^{13} \mathrm{C}$ to ${ }^{12} \mathrm{C}\left(\delta^{13} \mathrm{C}\right)$ in marine carbonates is sensitive to differences between the global burial flux of inorganic carbon (primarily as carbonate minerals) and the burial flux of organic carbon, which is isotopically light due to fractionations associated with photosynthetic carbon fixation (Kump \& Arthur, 1999). Hence, Phanerozoic $\delta^{13} \mathrm{C}$ trends may record changes in primary productivity, burial efficiency, and carbonate sedimentation rate, all of which are influenced by numerous other factors. Short-term $\delta^{13} \mathrm{C}$ excursions (i.e., drastic changes) can also be driven by volcanic injections of isotopically light $\mathrm{CO}_{2}$ or rapid $\mathrm{CO}_{2}$ drawdown through silicate weathering (Kump $\&$ Arthur, 1999). Because they are governed by relatively complex source-sink dynamics, $\delta^{13} \mathrm{C}$ trends are not as easily interpreted as $\delta^{18} \mathrm{O}$ trends, but we include this proxy because many extinction events (e.g., Ordovician-Silurian, Late Devonian, Late Permian, and Triassic-Jurassic events) are associated with either positive or negative $\delta^{13} \mathrm{C}$ excursions (Stanley, 2010) and such excursions are frequently interpreted as the signature of broad-scale environmental change.

As with $\delta^{13} \mathrm{C}$, shifts in $\delta^{34} \mathrm{~S}$ are commonly associated with major extinction events (Kaiho et al., 2006; Shen et al., 2011; Hammarlund et al., 2012), origination events (Cárdenas \& Harries, 2010), and biodiversity changes (Hannisdal, 2011; Hannisdal \& Peters, 2011) in the marine fossil record. The ratio of ${ }^{34} \mathrm{~S}$ to ${ }^{32} \mathrm{~S}\left(\delta^{34} \mathrm{~S}\right)$ in carbonate-associated sulfate is controlled by complex source-sink dynamics in the global sulfur cycle and is further complicated by the likelihood that marine sulfate residence times have varied through time, due to long-term changes in the size of the marine sulfate reservoir (Gill et al., 2007). $\delta^{34} \mathrm{~S}$ trends are commonly interpreted to reflect changes in the global pyrite burial flux, because sedimentary pyrite is isotopically light relative to seawater sulfate. Water-column pyrite can only precipitate in the presence of free $\mathrm{H}_{2} \mathrm{~S}$, and hence, $\delta^{34} \mathrm{~S}$ potentially provides information about the proportion of the global oceans affected by anoxia and euxinia. However, $\delta^{34} \mathrm{~S}$ is also sensitive to changes in the sulfate burial flux, the size of the marine $\mathrm{H}_{2} \mathrm{~S}$ reservoir, and the weathering flux of sulfide-bearing sedimentary rocks (Bottrell \& Newton, 2006). Despite the difficulty interpreting $\delta^{34} \mathrm{~S}$ trends in a straightforward manner, we include it here because of its link, however indirect, to the mean oxygenation state of the global oceans and because 
several important extinction events (e.g., Ordovician-Silurian, Late Permian events) are associated with $\delta^{34}$ S excursions.

To calculate observed extinction rate, we extracted data from the Paleobiology Database (http://paleodb.org) on June 3, 2014. These data include all Phanerozoic occurrences of marine bivalves and gastropods, excluding genera listed in quotation marks or qualified as '?' , 'cf.', or 'aff.'. We quantified observed extinction rate using the boundary-crosser metric (Bambach, 1999; Foote, 2000), which calculates the number of taxa that range completely through a particular time interval relative to the total number that cross into the interval (i.e., eliminating taxa that occur in only one interval). Time intervals in which extinction selectivity, environmental proxies, and observed extinction rate were assessed were referenced to one of 80 time intervals, primarily international geological stages, which span from the Ordovician through the Pleistocene (interval duration ranges from 1.5 to $19 \mathrm{Myr}$ and median duration is 5.3 Myr; Hannisdal \& Peters, 2011).

Changes in mean ocean $\mathrm{pH}$ and carbonate saturation state are of concern in modern oceans and have been implicated in several major extinction events, including the Late Permian and Triassic-Jurassic events (Harnik et al., 2012a,b). Recent advances in the analysis of $\delta^{11} \mathrm{~B}$ in carbonates, which is sensitive to seawater $\mathrm{pH}$, hold potential for defining a Phanerozoic ocean $\mathrm{pH}$ curve, but at present no such synthesis exists. However, several large acidification events have been identified based on a variety of geochemical and sedimentological criteria (Kiessling \& Simpson, 2011). We flagged these large acidification events in our dataset and treated ocean acidification as a categorical covariate (i.e., present/absent). We analyzed observed extinction rate and geochemical proxies as global stage-level averages (see Table S2).

\section{Statistical analyses}

We pooled log-odds ratios across studies and used inversevariance-weighted random-effect meta-regression (Hedges, 1983; Cooper et al., 2009) implemented in the metafor package (Viechtbauer, 2010) in R version 2.14.2 (R Core Team, 2015) to evaluate evidence of the drivers of extinction selectivity. Metaregression models are meta-analytic models that include covariates, similar to the way in which linear regression extends the estimation of a global mean (an intercept only) to include covariates. We first examined whether effect sizes varied substantially with factors related to the spatial, temporal, or taxonomic scope of the particular studies included in the metaanalysis. Using a chi-square test, we compared the base model (a single meta-analytic mean only) with meta-regression models including covariates for Linnaean hierarchical level (whether studies were performed using species vs. genera), molluscan class (whether studies focused on bivalves vs. gastropods), geographic scope (whether studies were performed at a regional vs. global level), and temporal resolution (whether studies were performed within a single geologic stage vs. multiple geologic stages). Chi-square tests revealed that these factors did not have a significant effect on extinction selectivity (see Table S3). We therefore excluded them from subsequent analyses.
Several studies included in the database contributed multiple effect sizes to the extinction selectivity analyses. This dependence may complicate the above analyses that assume independence among effect-size estimates, because a study may use data-selection criteria and statistical approaches that render effect sizes more similar to each other than would be expected if the effect sizes were drawn from independent studies. To test the sensitivity of our results to this possible covariance within studies, we fit separate hierarchical Bayesian models that account for study-level dependence using the metahdep package for $\mathrm{R}$ (Stevens \& Nicholas, 2011). These models account for possible study-level dependence by estimating a single covariance value between effect sizes from the same study in addition to the usual across-effect-size variance. As our conclusions remained the same, we report results from the simpler meta-analysis models that assume independence. We further assessed the effect that individual studies had on the results by systematically removing one study at a time and refitting the model (i.e., jackknifing). This approach provides an idea of how sensitive the results are to the exclusion of a particular study (see Fig. S1).

In many disciplines, studies reporting statistically significant outcomes are more likely to be published than those reporting nonsignificant outcomes. This 'file drawer' problem (Rosenthal, 1979; Scargle, 2000) could bias the results of the meta-analysis by overestimating extinction selectivity. We used funnel plots (Duval \& Tweedie, 2000) to explore the possibility of publication bias (see Fig. S2). Funnel plots show the distribution of effect sizes around the mean and identify deviations from the triangular expectation that (i) the effect sizes will be approximately normally distributed around the mean and (ii) larger studies will have effect sizes closer to the mean than smaller studies. Funnel plots for both geographic range and life-habit selectivity suggest that neither were noticeably affected by the 'file drawer problem' (Fig. S2).

We then evaluated the effect of environmental conditions that are hypothesized to influence extinction selectivity. For geographic range size, we used a meta-regression model to evaluate the effect of ocean acidification (large event or no large event as defined by Kiessling \& Simpson, 2011) and observed extinction rate, $\delta^{18} \mathrm{O}, \delta^{34} \mathrm{~S}$, and $\delta^{13} \mathrm{C}$ on extinction selectivity. Our degrees of freedom were reduced in the lifehabit model compared to the geographic range model because we had fewer effect sizes ( $\mathrm{n}=46$ for life habit vs. $n=80$ for geographic range size. Thus, to maintain statistical power, we eliminated one environmental proxy from the life-habit model. We chose to eliminate $\delta^{13} \mathrm{C}$ because, of the environmental proxies we examined, carbon cycling is more difficult to interpret and explicitly link to drivers of modern extinction in the oceans.

All code to reproduce our analysis is available at: https:// github.com/jebyrnes/ext-meta.

\section{Results}

On average, broad-ranging taxa are significantly more likely to survive extinction events than narrow-ranging taxa (Figs 1a, 2; estimate of log-odds ratio $=1.05,95 \%$ 
confidence interval $(\mathrm{CI})=0.84-1.25$, (odds ratio: 2.8, $95 \% \mathrm{CI}=2.3-3.5)$ ). When pooled across intervals characterized by different environmental conditions, there is no significant difference in extinction selectivity according to life habit (Figs 1b, 3; estimate of log-odds ratio $=-0.06,95 \% \mathrm{CI}=-0.32-0.20)$.

The variation in log-odds ratios throughout the Phanerozoic (Fig. 1a) suggests that the importance of geographic range in promoting survivorship may vary across different extinction events or geological stages, but not with any discernible trend through time (Fig. 1a). We did not find strong evidence for an effect of observed extinction rate on geographic range or lifehabit extinction selectivity (Figs 1, 4; Table S4). Our meta-regression shows no statistically significant relationships between geographic range selectivity and environmental proxies (Fig. 4a; Table S4a). Although the relationship with $\delta^{34} S$ is borderline statistically significant (estimate of log-odds ratio: $-0.07,95 \%$ confidence interval $(\mathrm{CI})=-0.13-0.001)$, it does not alter the direction of selectivity (i.e., although extinction selectivity appears to weaken slightly, broad-ranging taxa are still significantly more buffered from extinction than narrow taxa within the observed range of $\delta^{34}$ S, see Fig. S3).

In contrast, we found some evidence suggesting a weak relationship between environmental conditions and the selectivity of extinction with respect to life habit
(Fig. 4b, Table S4b). Our data show a significant positive association between $\delta^{18} \mathrm{O}$ and epifaunal survivorship (Fig. 4b). Accounting for all other predictors, decreases in $\delta^{18} \mathrm{O}$ (tied to climate warming) corresponded to preferential infaunal survivorship; increases in $\delta^{18} \mathrm{O}$ (tied to climate cooling) were associated with less selectivity (Fig. 5a; log-odds ratio: 0.42, 95\% CI $=0.03-0.81$ ). We used the detrended residuals of $\delta^{18} \mathrm{O}$ to account for the long-term Phanerozoic trend toward heavier values, which is controversial and poorly understood (Jaffrés et al., 2007). These residuals yielded even stronger results (Fig. 5b; Table S5b), such that increases in detrended $\delta^{18} \mathrm{O}$ (tied to climate cooling) corresponded to preferential epifaunal survivorship. Once again, decreases in detrended $\delta^{18} \mathrm{O}$ (tied to climate warming) corresponded to preferential infaunal survivorship (Fig. 5b; log-odds ratio: 0.52, 95\% $\mathrm{CI}=0.14-0.90)$. We did not find strong evidence that life-habit selectivity was correlated with changes in $\delta^{34} S$ or ocean acidification (Fig. 4b, Table S4b), or displayed any specific trend through time (Fig. 1b).

\section{Discussion}

Our meta-analysis reveals remarkable consistency in the link between geographic range and extinction selectivity throughout the past 500 million years. On aver-

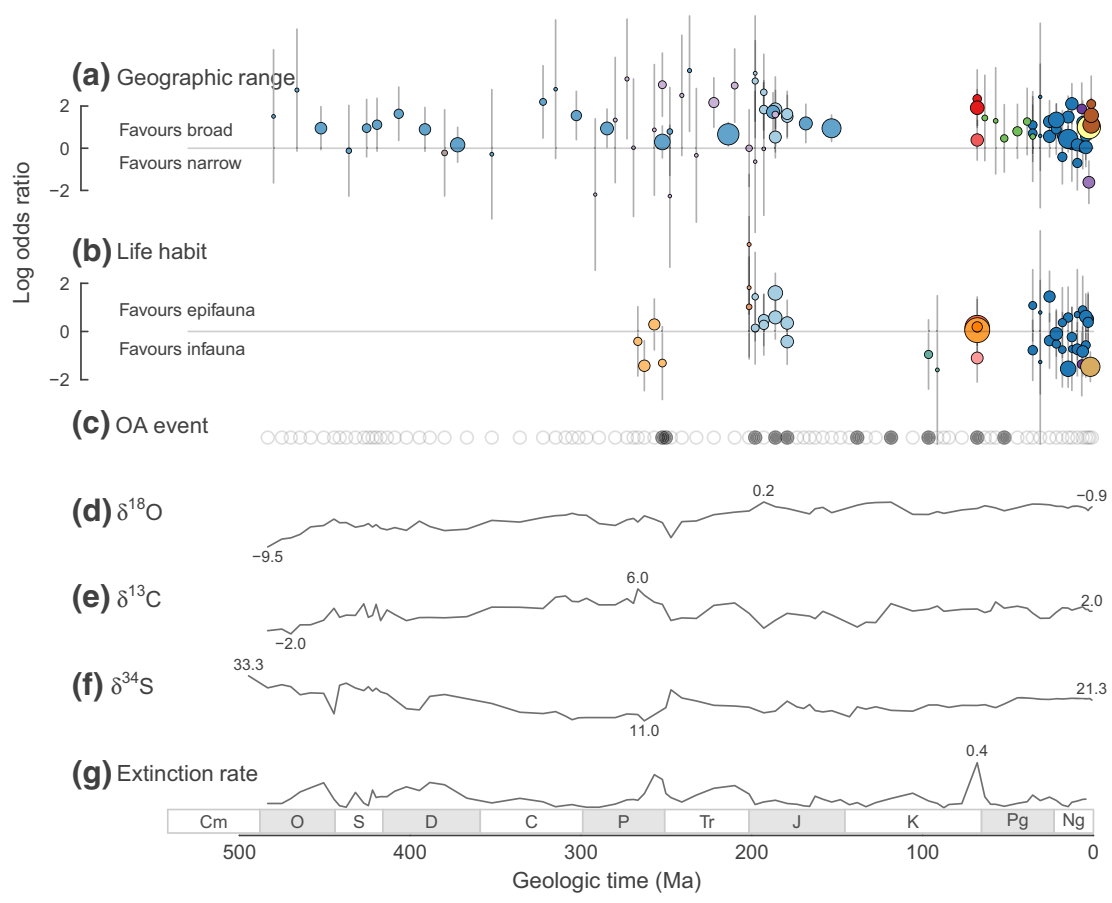

Fig. 1 Summary of extinction selectivity, environmental proxies, and observed extinction rate throughout the Phanerozoic. (a) Logodds ratios for geographic range selectivity $( \pm 95 \% \mathrm{CI})$, (b) log-odds ratios for life-habit selectivity ( $\pm 95 \% \mathrm{CI})$, (c) ocean acidification events (OA), (d) $\delta^{18} \mathrm{O}$, (e) $\delta^{13} \mathrm{C}$, (f) $\delta^{34} \mathrm{~S}$, (g) boundary crosser observed extinction rates for bivalve and gastropod genera. In panels a and $b$, we indicate more certain effect sizes with larger-area circles. Point shading represents study ID (see Fig. 5). 


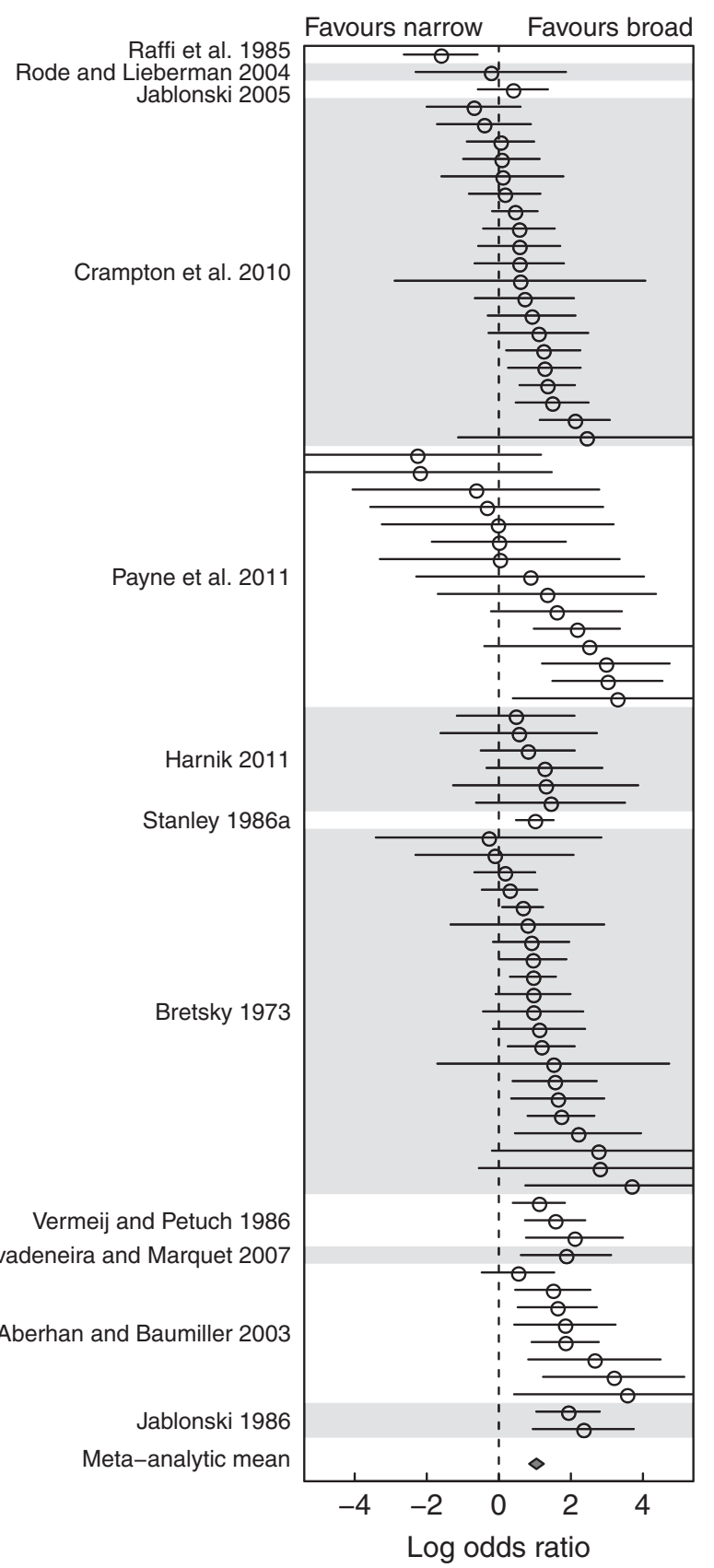

Fig. 2 Log-odds ratios by individual study for geographic range selectivity. Each data point represents the log-odds ratio $( \pm 95 \% \mathrm{CI})$ for a single test of extinction selectivity within a publication; publications can yield multiple data points corresponding to different geological stages, locations, and/or study organisms. Effect sizes are grouped by study (indicated with alternating shading) and studies are arranged from top to bottom in order of mean log-odds ratio. The diamond on the far right represents the meta-analytic mean logodds ratio $( \pm 95 \%$ CI $)$ across all effect sizes. Broad-ranging taxa are significantly more likely to survive than narrowranging taxa.

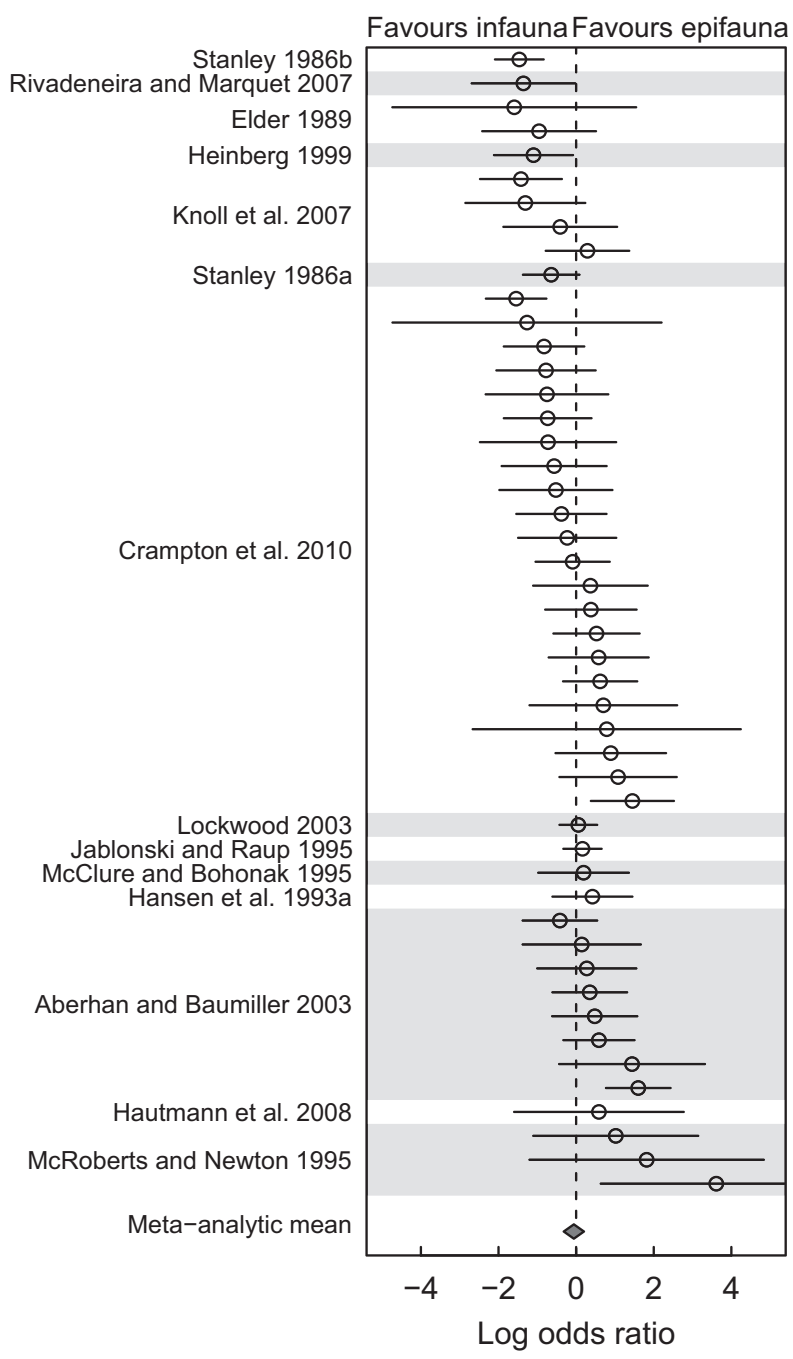

Fig. 3 Log-odds ratios by individual study for life-habit selectivity. Each data point represents the log-odds ratio ( $\pm 95 \% \mathrm{CI})$ for a single test of extinction selectivity within a publication; publications can yield multiple data points corresponding to different geological stages, locations, and/or study organisms. Effect sizes are grouped by study (indicated with alternating shading) and studies are arranged from top to bottom in order of mean log-odds ratio. The diamond on the far right represents the meta-analytic mean log-odds ratio $( \pm 95 \% \mathrm{CI})$ across all effect sizes. On average, extinction is not selective according to life habit.

age, broad-ranging taxa have three times the odds of surviving an extinction event relative to narrow-ranging taxa. Importantly, the association between extinction selectivity and geographic range exists regardless of prevailing environmental conditions.

Although taxa with broader ranges are more likely to be preserved and subsequently sampled in the fossil record (Koch, 1987; Russell \& Lindberg, 1988a,b; Raup, 

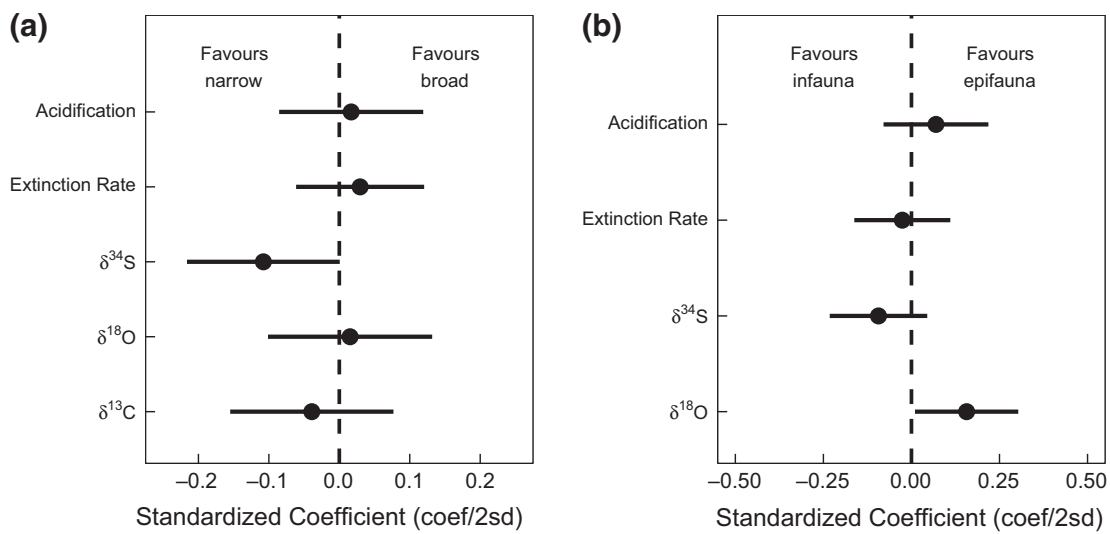

Fig. 4 Coefficients relating environmental proxies to extinction selectivity according to geographic range size (a) and life habit (b). Points represent standardized regression coefficient estimates and lines represent 95\% CI. We standardized the regression coefficients by subtracting the mean and dividing by two standard deviations for all continuous variables (i.e., 'coef/2sd'), making the magnitude of the coefficients approximately comparable (Gelman, 2008). We provide unstandardized coefficients and CI in Table S4.
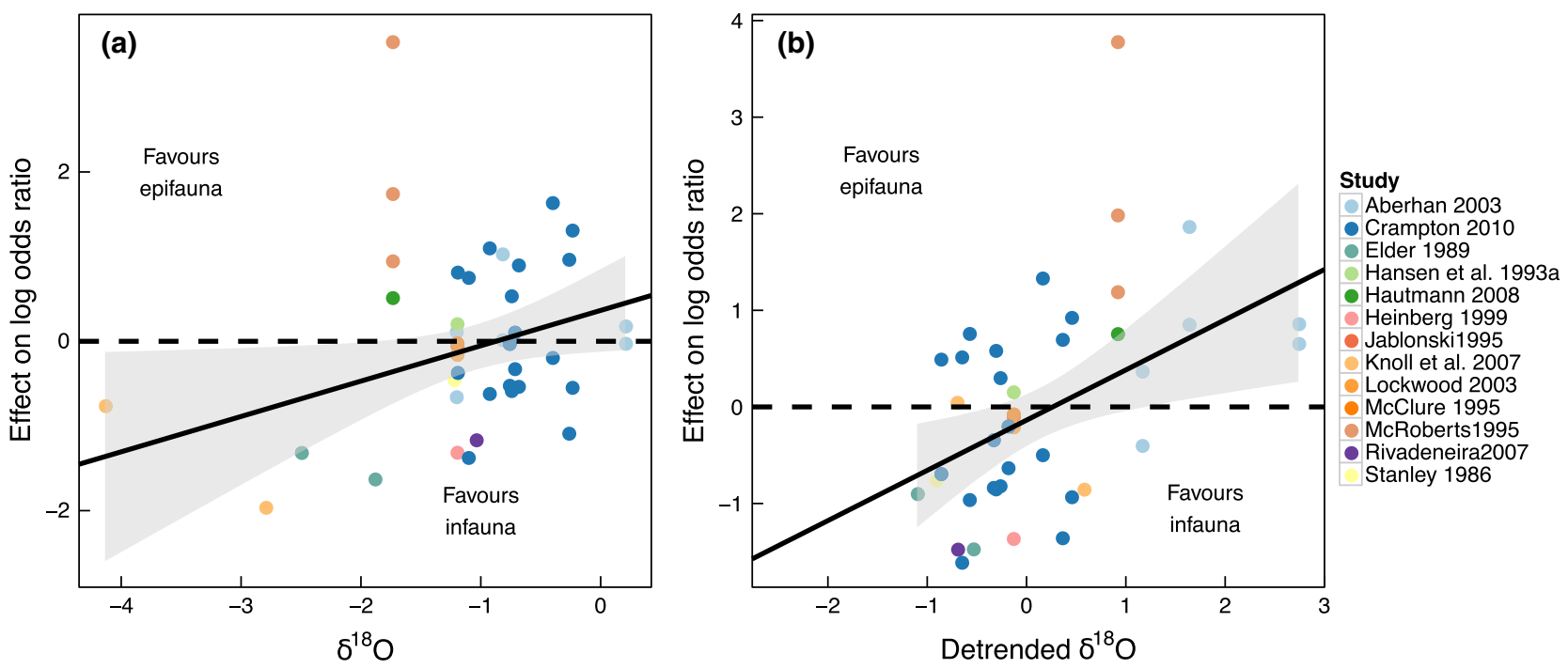

Fig. 5 Component + Residual + Intercept plots for life-habit selectivity models for $\delta^{18} \mathrm{O}$ (a) and detrended $\delta^{18} \mathrm{O}$ (b). This plot illustrates the sum of the intercept coefficient plus the effect of $\delta^{18} \mathrm{O}$ (a) or detrended $\delta^{18} \mathrm{O}(\mathrm{b})$ plus the remaining model residuals. This illustrates the effect of $\delta^{18} \mathrm{O}$ (and detrended $\delta^{18} \mathrm{O}$ ) plus unexplained residual variation in the data. Point shading represents study ID. Lines indicate the fitted model, with shaded regions representing 95\% CI. (a) Decreases in $\delta^{18} \mathrm{O}$ (tied to climate warming) corresponded to preferential infaunal survivorship. Increases in $\delta^{18} \mathrm{O}$ (tied to climate cooling) were not significantly selective. (b) Using the detrended data, increases in detrended $\delta^{18} \mathrm{O}$ (tied to climate cooling) corresponded to preferential epifaunal survivorship. Once again, decreases in detrended $\delta^{18} \mathrm{O}$ (tied to climate warming) corresponded to preferential infaunal survivorship.

1994; Foote, 1997), the pattern of extinction selectivity documented here is unlikely to result from such sampling artifacts. Several individual studies have attempted to control for sampling and preservational biases, but all still report a strong correlation between geographic range and extinction selectivity (Payne \& Finnegan, 2007; Rivadeneira \& Marquet, 2007; Crampton et al., 2010; Harnik, 2011).

The absence of any discernable links between geographic range extinction selectivity and global environmental state may suggest that environmental changes influencing the proxies we examined exert little effect on extinction selectivity related to geographic range. If all taxa are affected equally by an environmental change without regard to geographic range, this would not alter the preexisting ratio of extinction probabilities. Alternatively, this pattern may be the result of more complex causal relationships. For example, an interval of warming could drive sea-level rise, thereby opening more habitat and potentially reducing the 
extinction of spatially restricted endemics. However, endemic taxa restricted to high latitudes may be effectively trapped, unable to shift range when biogeographic boundaries migrate (Parmesan, 2006; Cheung et al., 2009). Direct and indirect effects of climate change, therefore, may not additively drive extinction selectivity in any one direction and the strength of selectivity may change in different regions.

Associations between fossil diversity and environmental conditions are frequently assessed using globally averaged environmental proxies (Peters \& Foote, 2002; Mayhew et al., 2008; Hannisdal \& Peters, 2011; Peters et al., 2013), although the residence times and expected geographic and environmental variability of the relevant proxies vary considerably. In this study, extinction selectivity data are drawn from spatially regional to global and temporally discrete to averaged extinction events, whereas all environmental proxy data are global (or low latitude in distribution) and averaged over millions of years within each geologic stage. It is therefore possible that our finding that geographic range selectivity does not vary with environmental conditions may reflect some mismatch of temporal and spatial scale between our extinction and environmental proxy data. We found no evidence that either geographic scope (i.e., regional vs. global studies) or temporal resolution (i.e., single vs. multi-stage studies) significantly affected geographic range effect size in our meta-analysis. Nevertheless, it is important to bear in mind that our spatially and temporally averaged environmental proxy dataset may miss geologically rapid and/or geographically focused perturbations that would be apparent at higher resolution (Jackson \& Johnson, 2000). Additional analyses of cases in which environmental proxy data and taxon ranges can be directly compared at the regional scale would be informative, but at present only a small handful of such cases exist (e.g., Jin et al., 2000; Xie et al., 2007).

Our meta-analysis did not reveal a statistically significant relationship between extinction selectivity and observed extinction rate. This is surprising as past work has suggested that traits promoting survivorship during background intervals, including geographic range, may not promote survivorship across mass extinction events (Jablonski, 1986a,b, 2005; Gould, 2002; Payne \& Finnegan, 2007). While two extinction events do coincide with lower-than-average extinction selectivity related to geographic range (both regional events during the Neogene), there is no consistent relationship across all intervals considered here. The majority of studies positing that patterns of extinction selectivity differ between background and mass extinctions do not incorporate environmental conditions into their analyses. This difference may explain why our analysis does not detect a relationship between observed patterns of extinction selectivity and observed extinction rate. A regional-scale analysis of extinction selectivity incorporating both extinction rate and environmental proxies would help further clarify whether the reduction in selectivity observed during various time intervals is more directly tied to particular environmental conditions rather than observed extinction rate.

No significant association between molluscan lifehabit and extinction selectivity was evident from our meta-analysis when we pooled across all studies. However, once we incorporated observed extinction rate, ocean acidification, $\delta^{18} \mathrm{O}$, and $\delta^{34} \mathrm{~S}$, an overall pattern of selectivity emerged. Preferential survivorship shifts from favoring epifaunal taxa during cooler intervals (or intervals with increasing continental ice volume), to favoring infaunal taxa during warmer intervals (or intervals with decreasing continental ice volume). This pattern is consistent with latitudinal diversity gradients in fossil bivalves, which suggest that infaunal species outnumbered epifauna in tropical latitudes, while the opposite was true in polar latitudes, at least for the Late Jurassic and Late Cretaceous (Crame, 1996, 2000, 2002; Jablonski, 2005). The proximal mechanism driving these patterns is unclear, in part because infaunal species dominate at all latitudes by the Recent (Roy et al., 2000; Crame, 2002). This pattern could be driven by differences in $\mathrm{pCO}_{2}$ sensitivity in infaunal versus epifaunal mollusks, especially bivalves. When episodes of climate warming are associated with increased $\mathrm{CO}_{2}$, it can lead to $\mathrm{CO}_{2}$ poisoning, or hypercapnia, in marine organisms. Infaunal taxa, including bivalves, regularly encounter elevated $\mathrm{pCO}_{2}$ levels in their habitats, in addition to generating high levels of $\mathrm{CO}_{2}$ in metabolic response to burrowing (Knoll et al., 1996, 2007; Widdicombe \& Spicer, 2008). Extant epifaunal bivalves, as a rule, do not encounter such elevated $\mathrm{pCO}_{2}$ levels, which may explain why epifaunal survivorship is reduced during warming intervals. Alternatively, warm climate states may be associated with reduced overturning circulation and less oxygenation of the shelves, especially the deep shelves. Because infaunal taxa deal with anoxia and the associated pore water enriched in $\mathrm{H}_{2} \mathrm{~S}$ more often, perhaps they do better than epifaunal taxa in a warm climate state (see discussion in McRoberts \& Newton, 1995; Aberhan \& Baumiller, 2003; Rivadeneira \& Marquet, 2007). Under the former scenario, we might expect to also observe a relationship between selectivity and OA, whereas under the latter scenario, we might expect a relationship with $\delta^{34} \mathrm{~S}$; however, in neither case is this observed. The former scenario is also undermined by the fact that infaunal taxa access water and nutrients at the sediment-water interface via their siphons. Future research 
could address this by contrasting in detail the physiological responses of infaunal and epifaunal bivalves to different environmental regimes.

Several of the data points that display low residual $\log$-odds ratios and low $\delta^{18} \mathrm{O}$ values (i.e., that anchor the lowest left quadrant of Fig. 5a) are derived from the Knoll et al.'s (2007) study of the Late Permian time interval. When this study is removed from the analysis, the relationship between $\delta^{18} \mathrm{O}$ and selectivity weakens (Fig. S1, compare to Fig. 4b). Although a link between $\mathrm{CO}_{2}$ tolerance and infaunality is often referred to in the literature (Knoll et al., 1996, 2007), few empirical studies exist to support it (Widdicombe et al., 2011). In fact, Clapham \& Payne's (2011) work on the Changhsingian (End Permian) extinction suggests that infaunal bivalves may have experienced greater extinction during the latest Permian than epifaunal bivalves. Despite this, the inclusion of the Knoll et al. (2007) study in this metaanalysis is warranted because (i) it is one of the few studies focusing on the intervals before and during a particularly catastrophic event and (ii) the studies targeting the time interval that follows (Triassic; McRoberts \& Newton, 1995; Hautmann et al., 2008) yield similar results. Until we have a better understanding of the physiological response of mollusks living below and above the sediment-water interface, especially to hypercapnia vs. anoxia, it may be difficult to interpret these results in detail.

When extinction selectivity is tracked across the Phanerozoic, our meta-analysis reveals no statistically significant trend in selectivity according to life habit. There is, however, a slight tendency for extinction selectivity to shift from preferential survivorship of infaunal taxa in the late Paleozoic to preferential survivorship of epifaunal taxa in the early Mesozoic and then back to preferential survivorship of infaunal taxa in the late Mesozoic or Cenozoic. The timing of this second shift may coincide with the Mesozoic marine revolution (Vermeij, 1977, 1987), a radiation of shell-crushing and boring predators that begins in the Late Triassic and is purported to lead to a decrease in the ratio of epifaunal relative to infaunal prey species by the Cretaceous (Thayer, 1979; Aberhan et al., 2006; Bush et al., 2007; Tackett \& Bottjer, 2012). Epifaunal bivalves, along with brachiopods, crinoids, and gastropods, are thought to have been heavily preyed upon throughout the Mesozoic marine revolution, driving the bivalves to invade deeper burrowing niches (Tackett \& Bottjer, 2012). Unfortunately, the lack of extinction selectivity studies focusing on the midJurassic to the Late Cretaceous makes this impossible to test using our current dataset.
Despite large differences in spatial and temporal scaling of extinction in ancient and modern oceans, our meta-analysis demonstrates that the predictors of selectivity can be effectively gleaned from 500 million years of earth history. Many of the environmental changes that are predicted to occur in the near future (e.g., ocean acidification, global climate change) have occurred multiple times in the past. The record of these past events provides conservation and global change biologists with opportunities to observe biotic responses and, in particular, patterns of extinction selectivity. The extent to which these patterns vary with environmental conditions provides useful data for models seeking to predict which organisms will go extinct in response to specific environmental changes. The crucial role that geographic range plays in survivorship of fossil marine organisms, regardless of environmental state, emphasizes that the preservation of range size should be a key priority in conservation (Mace et al., 2010). As nations struggle to support marine protected areas (MPAs) that cross international borders, the maintenance of overall range size, and connectivity among ranges, will only increase in importance (Wells \& Day, 2004; Moffitt et al., 2011; Berumen et al., 2012; Day \& Dobbs, 2013). The fact that geographic range is an accurate predictor of extinction over geologic time, regardless of environmental conditions, also supports its widespread use as a proxy for extinction selectivity by agencies such as the International Union for the Conservation of Nature (IUCN, 2014; see for example Cassini, 2011) and stresses the importance of targeting narrow-ranging taxa in conservation policymaking.

\section{Acknowledgements}

We thank James Crampton, Martin Aberhan, and Alycia Stigall. For their generous contributions of original data to our extinction selectivity database. This work is a product of the Determinants of Extinction in Ancient and Modern Seas Working Group supported by the National Evolutionary Synthesis Center, NSF \#EF-0905606. We thank Moriaki Yasuhara and two anonymous referees for insightful reviews. Additional support was provided by the Natural Sciences and Engineering Research Council of Canada to H.K.L., S.C.A., and Z. V.F.; the National System of Investigators of the National Research of the National Secretariat for Science, Technology and Innovation of Panama to A.O'D.; the Australian Research Council Centre of Excellence for Coral Reef Studies grant DP 130100250 to J.M.P.; the National Center for Ecological Analysis and Synthesis and MIT SeaGrant 2015-R/ RCM-39 for JEKB; and the Deutsche Forschungsgemeinschaft grant KI 806/7-1 to C.S. We thank the contributors to the Paleobiology Database and to OBIS. This article is Paleobiology Database Publication no. 229 


\section{References}

Aberhan M, Baumiller TK (2003) Selective extinction among Early Jurassic bivalves: a consequence of anoxia. Geology, 31, 1077 .

Aberhan M, Kiessling W, Fürsich FT (2006) Testing the role of biological interactions in the evolution of mid-Mesozoic marine benthic ecosystems. Paleobiology, 32, 259 277

Bacon GS, MacDonald BA, Ward JE (1998) Physiological responses of infaunal (Mya arenaria) and epifaunal (Placopecten magellanicus) bivalves to variations in the concentration and quality of suspended particles I. Feeding activity and selection. Journal of Experimental Marine Biology and Ecology, 219, 105-125.

Bambach RK (1999) Energetics in the global marine fauna: a connection between terrestrial diversification and change in the marine biosphere. Geobios, 32, 131-144.

Berumen ML, Almany GR, Planes S, Jones GP, Saenz-Agudelo P, Thorrold SR (2012) Persistence of self-recruitment and patterns of larval connectivity in a marine protected area network. Ecology and Evolution, 2, 444-452.

Blois JL, Zarnetske PL, Fitzpatrick MC, Finnegan S (2013) Climate change and the past, present, and future of biotic interactions. Science, 341, 499-504.

Bottrell SH, Newton RJ (2006) Reconstruction of changes in global sulfur cycling from marine sulfate isotopes. Earth-Science Reviews, 75, 59-83.

Broecker WS (1997) Thermohaline circulation, the Achilles heel of our climate system: will man-made $\mathrm{CO}_{2}$ upset the current balance? Science, 278, 1582-1588

Brook BW, Sodhi NS, Bradshaw CJA (2008) Synergies among extinction drivers under global change. Trends in Ecology and Evolution, 23, 453-460.

Bush AM, Bambach RK, Daley GM (2007) Changes in theoretical ecospace utilization in marine fossil assemblages between the mid-Paleozoic and late Cenozoic. Paleobiology, 33, 76-97.

Caldeira K, Wickett ME (2003) Oceanography: anthropogenic carbon and ocean $\mathrm{pH}$ Nature, 425, 365.

Cárdenas AL, Harries PJ (2010) Effect of nutrient availability on marine origination rates throughout the Phanerozoic eon. Nature Geoscience, 3, 430-434.

Cassini MH (2011) Ranking threats using species distribution models in the IUCN Red List assessment process. Biodiversity and Conservation, 20, 3689-3692.

Cheung WWL, Lam VWY, Sarmiento JL, Kearney K, Watson R, Pauly D (2009) Projecting global marine biodiversity impacts under climate change scenarios. Fish and Fisheries, 10, 235-251

Clapham ME, Payne JL (2011) Acidification, anoxia, and extinction: a multiple logistic regression analysis of extinction selectivity during the Middle and Late Permian. Geology, 39, 1059-1062.

Cooper H, Hedges L, Valentine J (eds) (2009) The Handbook of Research Synthesis and Meta-Analysis, vol. 113. Russel Sage Foundation, New York

Cooper RA, Maxwell PA, Crampton JS, Beu AG, Jones CM, Marshall BA (2006) Completeness of the fossil record: estimating losses due to small body size. Geology, 34, 241-244

Crame JA (1996) Evolution of high-latitude molluscan faunas. In: Origin and Evolutionary Radiation of the Mollusca (ed. Taylor JD), pp. 119-131. Oxford University Press, Oxford.

Crame JA (2000) Evolution of taxonomic diversity gradients in the marine realm: evidence from the composition of Recent bivalve faunas. Paleobiology, 26, 188 214

Crame JA (2002) Evolution of taxonomic diversity gradients in the marine realm: a comparison of Late Jurassic and Recent bivalve faunas. Paleobiology, 28, 184-207.

Crampton JS, Cooper R, Beu AG, Foote M, Marshall BA (2010) Biotic influences on species duration: interactions between traits in marine molluscs. Paleobiology, 36, 204-223

Day JC, Dobbs K (2013) Effective governance of a large and complex cross-jurisdictional marine protected area: Australia's Great Barrier Reef. Marine Policy, 41, $14-24$.

Duval S, Tweedie R (2000) Trim and fill: a simple funnel-plot-based method. Biometrics, 56, 455-463.

Finnegan S, Heim NA, Peters SE, Fischer WW (2012) Climate change and the selective signature of the Late Ordovician mass extinction. Proceedings of the National Academy of Sciences, 109, 6829-6834.

Finnegan S, Anderson SC, Harnik PG et al. (2015) Paleontological baselines for evaluating extinction risk in the modern oceans. Science, 348, 567-570.

Foote M (1997) Estimating taxonomic durations and preservation probability. Paleobiology, 23, 278-300.

Foote M (2000) Origination and extinction components of taxonomic diversity: general problems. Paleobiology, 26, 74-102.

Foote M, Raup DM (1996) Fossil preservation and the stratigraphic ranges of taxa Paleobiology, 22, 121-140.
Foote M, Sepkoski JJ (1999) Absolute measures of the completeness of the fossil record. Nature, 398, 415-417.

Gallagher WB (1991) Selective extinction and survival across the Cretaceous/Tertiary boundary in the northern Atlantic Coastal Plain. Geology, 19, 967-970.

Gelman A (2008) Scaling regression inputs by dividing by two standard deviations. Statistics in Medicine, 27, 2865-2873.

Gill BC, Lyons TW, Saltzman MR (2007) Parallel, high-resolution carbon and sulfur isotope records of the evolving Paleozoic marine sulfur reservoir. Palaeogeography, Palaeoclimatology, Palaeoecology, 256, 156-173.

Gould SJ (2002) The Structure of Evolutionary Theory. Belknap Press, Cambridge

Hallam A, Wignall PB (1999) Mass extinctions and sea-level changes. Earth-Science Reviews, 48, 217-250.

Hammarlund EU, Dahl TW, Harper DAT et al. (2012) A sulfidic driver for the endOrdovician mass extinction. Earth and Planetary Science Letters, 331-332, 128-139.

Hannisdal B (2011) Detecting common-cause relationships with directional information transfer. Geological Society, London, Special Publications, 358, 19-29.

Hannisdal B, Peters SE (2011) Phanerozoic earth system evolution and marine biodiversity. Science, 334, 1121-1124.

Harnik PG (2011) Direct and indirect effects of biological factors on extinction risk in fossil bivalves. Proceedings of the National Academy of Sciences, 108, 13594-13599.

Harnik PG, Lockwood R (2011) Extinction in the marine Bivalvia. Treatise on Invertebrate Paleontology Online, 29, 1-24.

Harnik PG, Lotze HK, Anderson SC et al. (2012a) Extinctions in ancient and modern seas. Trends in Ecology and Evolution, 27, 608-617.

Harnik PG, Simpson C, Payne JL (2012b) Long-term differences in extinction risk among the seven forms of rarity. Proceedings of the Royal Society of London. Series B Biological Sciences, 279, 4969-4976.

Harper E (1998) The fossil record of bivalve molluscs. In: The Adequacy of the Fossil Record, vol. 1998 (eds Donovan S, Paul C), pp. 243-267. John Wiley \& Sons Inc, Chichester.

Hautmann M, Stiller F, Huawei C, Jingeng S (2008) Extinction-recovery pattern of level-bottom faunas across the Triassic-Jurassic boundary in Tibet: implications for potential killing mechanisms. Palaios, 23, 711-718.

Hedges LV (1983) A random effects model for effect sizes. Psychological Bulletin, 93, 388-395.

Hoegh-Guldberg O, Mumby PJ, Hooten AJ et al. (2007) Coral reefs under rapid climate change and ocean acidification. Science, 318, 1737-1742.

Hollander DJ, McKenzie JA, Hsü KJ (1993) Carbon isotope evidence for unusual plankton blooms and fluctuations of surface water $\mathrm{CO}_{2}$ in "Strangelove Ocean" after terminal Cretaceous event. Palaeogeography, Palaeoclimatology, Palaeoecology, 104, 229-237.

IUCN (2014) IUCN Red List of Threatened Species. Version 2014. Version 1. IUCN 2014, 2010, Downloaded on 27th July 2012

Jablonski D (1986a) Background and mass extinctions: the alternation of macroevolutionary regimes. Science, 231, 129-133.

Jablonski D (1986b) Larval ecology and macroevolution in marine invertebrates. Bulletin of Marine Science, 39, 565-587.

Jablonski D (1989) The biology of mass extinction: a palaeontological view. Philosophical Transactions of the Royal Society of London. B, Biological Sciences, 325, 357-368.

Jablonski D (2005) Mass extinctions and macroevolution. Paleobiology, 31, 192-210.

Jablonski D, Lutz RA (1983) Larval ecology of marine benthic invertebrates: Paleobiological implications. Biological Reviews, 58, 21-89.

Jablonski D, Finarelli JA (2009) Congruence of morphologically-defined genera with molecular phylogenies. Proceedings of the National Academy of Sciences, 106, 8262-8266.

Jablonski D, Raup D (1995) Selectivity of end-Cretaceous marine bivalve extinctions. Science, 268, 389-391.

Jaffrés J, Shields G, Wallmann K (2007) The oxygen isotope evolution of seawater: a critical review of a long-standing controversy and an improved geological water cycle model for the past 3.4 billion years. Earth-Science Reviews, 83, 83-122.

Jin YG, Wang Y, Shang QH et al. (2000) Pattern of marine mass extinction near the Permian-Triassic boundary in South China. Nature, 289, 432-436.

Jackson J, Johnson K (2000) Life in the last few million years. Paleobiology, 26, 221-234. Jones KE, Purvis A, Gittleman JL (2003) Biological correlates of extinction risk in bats. The American Naturalist, 161, 601-614.

Kaiho K, Chen Z, Kawahata H, Kajiwara Y, Sato H (2006) Close-up of the end-Permian mass extinction horizon recorded in the Meishan section, South China: sedimentary, elemental, and biotic characterization and a negative shift of sulfate sulfur isotope ratio. Palaeogeography, Palaeoclimatology, Palaeoecology, 239, 396 405.

Kelley P, Hansen T (2003) The fossil record of drilling predation on bivalves and gastropods. In: Predator-Prey Interactions in the Fossil Record (eds Kelley P, Kowalewski M, Hansen TA), pp. 113-139. Springer, New York, USA. 
Kidwell SM (2001) Preservation of species abundance in marine death assemblages. Science, 294, 1091-1094

Kidwell SM (2002) Mesh-size effects on the ecological fidelity of death assemblages: a meta-analysis of molluscan live-dead studies. Geobios, 35, 107-119.

Kidwell SM (2005) Shell composition has no net impact on large-scale evolutionary patterns in mollusks. Science, 307, 914-917.

Kiessling W, Aberhan M (2007) Geographical distribution and extinction risk: lessons from Triassic-Jurassic marine benthic organisms. Journal of Biogeography, 34, 1473 1489.

Kiessling W, Simpson C (2011) On the potential for ocean acidification to be a general cause of ancient reef crises. Global Change Biology, 17, 56-67.

Kitchell J, Clark D, Gambos A (1986) Biological selectivity of extinction; a link between background and mass extinction. Palaios, 1, 504-511.

Knoll AH, Bambach R, Canfield D, Grotzinger J (1996) Comparative Earth history and Late Permian mass extinction. Science, 273, 452-457.

Knoll AH, Bambach RK, Payne JL, Pruss S, Fischer WW (2007) Paleophysiology and end-Permian mass extinction. Earth and Planetary Science Letters, 256, 295-313.

Koch CF (1987) Prediction of sample size effects on the measured temporal and geographic distribution patterns of species. Paleobiology, 13, 100-107.

Kowalewski M (2002) The fossil record of predation: an overview of analytical methods. Paleontological Society Special Papers, 8, 3-42.

Kump LR (1991) Interpreting carbon-isotope excursions: strangelove oceans. Geology, 19, 299.

Kump LR, Arthur MA (1999) Interpreting carbon-isotope excursions: carbonates and organic matter. Chemical Geology, 161, 181-198.

Liow LH (2007) Does versatility as measured by geographic range, bathymetric range and morphological variability contribute to taxon longevity? Global Ecology and Biogeography, 16, 117-128.

Lockwood R (2003) Abundance not linked to survival across the end-Cretaceous mass extinction: patterns in North American bivalves. Proceedings of the National Academy of Sciences, 100, 2478-2482.

Lockwood R (2008) Beyond the Big Five: extinctions as experiments in the history of life. Paleontological Society Papers, 14, 207-228.

Mace GM, Collen B, Fuller RA, Boakes EH (2010) Population and geographic range dynamics: implications for conservation planning. Philosophical Transactions of the Royal Society of London. B, Biological Sciences, 365, 3743-3751.

Mantel N, Haenszel W (1959) Statistical aspects of the analysis of data from retrospective studies of disease. Journal of the National Cancer Institute, 22, 719-748.

Mayhew PJ, Jenkins GB, Benton TG (2008) A long-term association between global temperature and biodiversity, origination and extinction in the fossil record. Proceedings of the Royal Society of London. Series B: Biological Sciences, 275, 47-53

McClenachan L, Cooper AB, Carpenter KE, Dulvy NK (2012) Extinction risk and bottlenecks in the conservation of charismatic marine species. Conservation Letters, 5 , 73-80.

McKinney ML (1997) Extinction vulnerability and selectivity: combining ecological and paleontoogical views. Annual Review of Ecology and Systematics, 28, 495-516.

McKinney ML (2001) Selectivity during extinctions. In: Palaeobiology II (eds Briggs D, Crowther P), pp. 198-202. Blackwell Science Ltd, Malden, MA, USA.

McRoberts CA, Newton CR (1995) Selective extinction among end-Triassic European bivalves. Geology, 23, 102

Moffitt EA, Wilson White J, Botsford LW (2011) The utility and limitations of size and spacing guidelines for designing marine protected area (MPA) networks. Biological Conservation, 144, 306-318.

Montagna PA, Ritter C (2006) Direct and indirect effects of hypoxia on benthos in Corpus Christi Bay, Texas, U.S.A. Journal of Experimental Marine Biology and Ecology, 330, 119-131.

Newell N (1967) Revolutions in the history of life. Geological Society of America Special Papers, 89, 63-92.

O'Dea A, Jackson J (2009) Environmental change drove macroevolution in cupuladriid bryozoans. Proceedings of the Royal Society of London. Series B: Biological Sciences, 276, 3629-3634.

Orr JC, Fabry VJ, Aumont O et al. (2005) Anthropogenic ocean acidification over the twenty-first century and its impact on calcifying organisms. Nature, 437, 681-686.
Parmesan C (2006) Ecological and evolutionary responses to recent climate change. Annual Review of Ecology, Evolution, and Systematics, 37, 637669.

Payne JL, Finnegan S (2007) The effect of geographic range on extinction risk during background and mass extinction. Proceedings of the National Academy of Sciences, 104, 10506-10511.

Peters SE, Foote M (2002) Determinants of extinction in the fossil record. Nature, 416 420-424.

Peters SE, Kelly DC, Fraass AJ (2013) Oceanographic controls on the diversity and extinction of planktonic foraminifera. Nature, 493, 398-401.

Prokoph M, Shields G, Veizer J (2008) Compilation and time-series analysis of a marine carbonate $\delta^{18} \mathrm{O}, \delta^{13} \mathrm{C},{ }^{87} \mathrm{Sr} /{ }^{86} \mathrm{Sr}$ and $\delta^{34} \mathrm{~S}$ database through Earth history. Earth-Science Reviews, 87, 113-133.

Purvis A, Gittleman JL, Cowlishaw G, Mace GM (2000) Predicting extinction risk in declining species. Proceedings of the Royal Society of London. Series B: Biological Sciences, 267, 1947-1952.

R Core Team (2015) R: A Language and Environment for Statistical Computing, R Foundation for Statistical Computing, Vienna, Austria. \{ISBN\} 3-900051-07-0. Available at: http://www.R-project.org (accessed 15 January 2015).

Raup DM (1994) The role of extinction in evolution. Proceedings of the National Academy of Sciences, 91, 6758-6763.

Rivadeneira MM, Marquet PA (2007) Selective extinction of late Neogene bivalves on the temperate Pacific coast of South America. Paleobiology, 33, 455-468.

Rockström J, Steffen W, Noone K et al. (2009) Planetary boundaries:exploring the safe operating space for humanity. Ecology and Society, 14, 32.

Roopnarine P (1997) Endemism and extinction of a new genus of chionine (Veneridae: Chioninae) bivalve from the late Neogene of Venezuela. Journal of Paleontology, 71, 1039-1046.

Rosenthal R (1979) The file drawer problem and tolerance for null results. Psychologi cal Bulletin, 86, 638-641.

Rosenzweig ML (1995) Species Diversity in Space and Time. Cambridge University Press, Cambridge.

Roy K, Jablonski D, Valentine JW (2000) Dissecting latitudinal diversity gradients: functional groups and clades of marine bivalves. Proceedings of the Royal Society of London. Series B: Biological Sciences, 267, 293-299.

Ruhl M, Bonis NR, Reichart G-J, Sinninghe Damsté JS, Kürschner WM (2011) Atmospheric carbon injection linked to end-Triassic mass extinction. Science, 333, 430-434.

Russell MP, Lindberg DR (1988a) Estimates of species durations. Science, 240, 969.

Russell MP, Lindberg DR (1988b) Real and random patterns associated with molluscan spatial and temporal distributions. Paleobiology, 14, 322-330.

Scargle JD (2000) Publication bias: the "File Drawer" problem in scientific inference. Journal of Scientific Exploration, 14, 91-106.

Shaffer G, Olsen SM, Pedersen JOP (2009) Long-term ocean oxygen depletion in response to carbon dioxide emissions from fossil fuels. Nature Geoscience, 2, 105-109.

Shen S, Crowley J, Wang Y et al. (2011) Calibrating the End-Permian mass extinction. Science, 9, 1367-1372.

Simpson C, Harnik PG (2009) Assessing the role of abundance in marine bivalve extinction over the post-Paleozoic. Paleobiology, 35, 631-647.

Stanley SM (1977) Trends, rates, and patterns of evolution in the Bivalvia. In: Patterns of Evolution, as Illustrated by the Fossil Record (ed. Hallam A), pp. 209-250. Elsevier Ltd., New York.

Stanley SM (1982) Macroevolution and the fossil record. Evolution, 36, 460-473.

Stanley SM (1986a) Anatomy of a regional mass extinction: Plio- Pleistocene decimation of the Western Atlantic Bivalve Fauna. Palaios, 1, 17-36.

Stanley SM (1986b) Population size, extinction, and speciation: the fission effect in Neogene Bivalvia. Paleobiology, 12, 89-110.

Stanley SM (2010) Relation of Phanerozoic stable isotope excursions to climate, bacterial metabolism, and major extinctions. Proceedings of the National Academy of Sciences, 107, 19185-19189.

Stevens J, Nicholas G (2011) Metahdep: Hierarchical Dependence in Meta-analysis. $R$ package version 1.16 .0

Tackett L, Bottjer D (2012) Faunal succession of Norian (Late Triassic) level-bottom benthos in the Lombardian Basin: implications for the timing, rate, and nature of the early Mesozoic marine revolution. Palaios, 27, 585-593. 
Thayer CW (1979) Biological bulldozers and the evolution of marine benthic communities. Science, 203, 458-461.

Valentine JW (1989) How good was the fossil record? Clues from the California Pleistocene. Paleobiology, 15, 83-94.

Valentine JW, Jablonski D, Kidwell S, Roy K (2006) Assessing the fidelity of the fossil record by using marine bivalves. Proceedings of the National Academy of Sciences, 103, 6599-6604.

Veizer J, Bruckschen P, Pawellek F et al. (1997) Oxygen isotope evolution of Phanerozoic seawater. Palaeogeography, Palaeoclimatology, Palaeoecology, 132, 159172

Velasco LA, Navarro JM (2003) Energetic balance of infaunal (Mulinia edulis King, 1831) and epifaunal (Mytilus chilensis Hupé, 1854) bivalves in response to wide variations in concentration and quality of seston. Journal of Experimental Marine Biology and Ecology, 296, 79-92.

Vermeij G (1977) The Mesozoic marine revolution: evidence from snails, predators and grazers. Paleobiology, 3, 245-258.

Vermeij G (1987) The dispersal barrier in the tropical Pacific: implications for molluscan speciation and extinction. Evolution, 4, 1046-1058.

Viechtbauer W (2010) Conducting meta-analyses in R with the metafor package. Journal of Statistical Software, 36, 1-48.

Wagner P, Aberhan M, Hendy A, Kiessling W (2007) The effects of taxonomic standardization on sampling-standardized estimates of historical diversity. Proceeding of the Royal Society B: Biological Sciences, 274, 439-444.

Wells S, Day J (2004) Application of the IUCN protected area management categories in the marine environment. Parks, 14, 28-38.

Widdicombe S, Spicer JI (2008) Predicting the impact of ocean acidification on benthic biodiversity: what can animal physiology tell us? Journal of Experimental Marine Biology and Ecology, 366, 187-197.

Widdicombe S, Spicer JI, Kitidis V (2011) Effects of ocean acidification on sediment fauna. In: Ocean Acidification, (eds Gattuso JP, Hansson L), pp. 176-191. Oxford University Press, UK.

Wignall PB, Sun Y, Bond DPG et al. (2009) Volcanism, mass extinction, and carbon isotope fluctuations in the Middle Permian of China. Science, 324, 11791182.

Xie S, Pancost RD, Huang X et al. (2007) Molecular and isotopic evidence for episodic environmental change across the Permo/Triassic boundary at Meishan in South China. Global and Planetary Change, 55, 56-65.

\section{Supporting Information}

Additional Supporting Information may be found in the online version of this article:

Table S1. Compilation of data synthesized on extinction selectivity according to geographic range and life habit and source from which they were compiled.

Table S2. Data compiled on observed extinction rate (Ext Rate), geochemical proxies $\left(\delta^{18} \mathrm{O}, \delta^{13} \mathrm{C}, \delta^{34} \mathrm{~S}\right)$ and ocean acidification (OA; Y: OA event recorded, N: no event recorded), listed chronologically.

Table S3. Differences in molluscan class (bivalve vs. gastropod), Linnaean hierarchical level (species vs. genera), geographic scope (regional vs. global), temporal resolution (single vs. multi-stage), and time (geological stage midpoint) on extinction selectivity effect sizes for (a) geographic range and (b) life habit analyses.

Table S4. Results of meta-analyses incorporating environmental covariates, including raw geochemical proxies.

Table S5. Results of meta-analyses incorporating environmental covariates, including detrended geochemical proxies.

Figure S1. Jackknife plot evaluating the impact of individual studies on extinction selectivity.

Figure S2. Testing for "file drawer" problem relating to publication bias.

Figure S3. Component-residual plot for geographic range selectivity and all model predictors.

Figure S4. Component-residual plot for life habit range selectivity and all model predictors. 